\title{
Antitumor effects of lapatinib (GW572016), a dual inhibitor of EGFR and HER-2, in combination with cisplatin or paclitaxel on head and neck squamous cell carcinoma
}

\author{
NORIO KONDO, MAMORU TSUKUDA, YUKARI ISHIGURO, MACHIKO KIMURA, \\ KYOKO FUJITA, ATSUKO SAKAKIBARA, HIDEAKI TAKAHASHI, \\ GABOR TOTH and HIDEKI MATSUDA \\ Department of Biology and Function in Head and Neck, Yokohama City University \\ Graduate School of Medicine, 3-9 Fukuura, Kanazawa-ku, Yokohama 236-0004, Japan
}

Received October 20, 2009; Accepted January 8, 2010

DOI: 10.3892/or_00000720

\begin{abstract}
The epidermal growth factor receptor (EGFR) and a related family member, HER-2, are often overexpressed simultaneously in patients with a variety of malignant tumors, and the combination may cooperatively promote cancer cell growth and survival. Heterodimerization of EGFR and HER-2 has been known to create intense proliferative signals. Lapatinib (GW572016) is a small molecule that is administrated orally and functions as a reversible inhibitor of both EGFR and HER-2 tyrosine kinases. In the present study, we evaluated the antitumor effect of lapatinib on head and neck squamous cell carcinoma (HNSCC) cell lines in vitro and in vivo. In vivo we examined the antitumor effects of combined treatment with lapatinib and either cisplatin or paclitaxel. In vitro lapatinib displayed antiproliferative effects on HNSCC cells. The $\mathrm{IC}_{50}$ of lapatinib ranged between 13.6 and $60.2 \mu \mathrm{M}$ after $24-\mathrm{h}$ exposure to lapatinib. A correlation was not observed between results of in vitro proliferation assays for lapatinib and the expression of EGFR or HER-2. In vivo lapatinib displayed antitumor activity, and induced apoptosis in nude mice bearing an established xenograft of YCU-H891 cells. Lapatinib did not significantly inhibit angiogenesis. Combination treatment of lapatinib with cisplatin or paclitaxel enhanced antitumor activity mainly by inducing apoptosis. Inhibition of antiangiogenesis was observed only for combination treatment of lapatinib with paclitaxel (compared to vehicle control). These results suggest that: i) lapatinib has antitumor effects in vitro and in vivo; ii) lapatinib may be more effective in combination with cisplatin or paclitaxel;
\end{abstract}

Correspondence to: Dr Norio Kondo, Department of Biology and Function in Head and Neck, Yokohama City University Graduate School of Medicine, 3-9 Fukuura, Kanazawa-ku, Yokohama 236-0004, Japan

E-mail: t076022c@yokohama-cu.ac.jp

Key words: lapatinib, cisplatin, paclitaxel, head and neck squamous cell carcinoma, EGFR, HER-2 and iii) lapatinib might provide useful clinical benefits to HNSCC patients.

\section{Introduction}

Epidermal growth factor receptor (EGFR) and HER-2 belong to the HER family of receptor tyrosine kinases, which include EGFR (ErbB1 or HER-1), HER-2 (ErbB2), HER-3 (ErbB3), and HER-4 (ErbB4). Overexpression of EGFR has been observed frequently in head and neck squamous cell carcinomas (HNSCC) and EGFR overexpression is thought to be correlated with carcinogenesis, metastasis, clinical stage and poor prognosis (1-4). Overexpression of HER-2 has been noted in HNSCC (5-7), and HER-2 heterodimerization with EGFR may mediate disease progression $(6,7)$. Elevated expression of EGFR and/or HER-2 has been associated with tumor cell resistance to chemotherapy and radiotherapy (7-9). Therefore, EGFR and HER-2 are attractive targets for anticancer treatments.

Lapatinib is a dual inhibitor that targets the tyrosine kinase domains of both EGFR and HER-2 by interfering with adenosine triphosphate binding, thus blocking autophosphorylation and resultant downstream signaling activities, including cellular proliferation and survival (10). Lapatinib is approved by FDA for the treatment of metastatic breast cancer in combination with capecitabine. In head and neck cancer, a phase II study of patients with recurrent or metastatic EGFR and/or HER-2 expressing salivary grand carcinoma (11) and a phase I study of lapatinib in combination with chemoradiation in patients with locally advanced HNSCC (12) were reported. Targeting both EGFR and HER-2 in cancer treatment is reported to be efficacious for breast cancer, non-small cell lung cancer (NSCLC), prostate cancer, and vulvar squamous cell carcinoma (13-16). Based on the above findings, we targeted both EGFR and HER-2 in the treatment of HNSCC. We reported the antitumor effects of gefitinib combined with trastuzumab on HNSCC cells in vitro (17). Cell growth was significantly inhibited by the combination of gefitinib and trastuzumab in some HNSCC cell lines. In the present study, we examined antitumor effects of lapatinib, an inhibitor of tyrosine kinases of both EGFR and HER-2, on HNSCC cell 
lines in vitro and in vivo. We also examined antitumor effects of the combined treatment of lapatinib with cisplatin or paclitaxel in a xenograft model of HNSCC cells in vivo.

\section{Materials and methods}

Drugs. Lapatinib (GW572016) was provided by GlaxoSmithKline Pharmaceuticals (Research Triangle Park, NC). For the antiproliferative assay, stock solution $(10 \mathrm{mM})$ was made in $100 \%$ dimethyl sulfoxide (DMSO) and diluted with culture media. Cisplatin $\left(\right.$ Briplatin $\left.^{\circledR}\right)$ and paclitaxel $\left(\right.$ Taxol $\left.^{\circledR}\right)$ were purchased from Bristol-Myers Squib (Park Avenue, NY). Cisplatin and paclitaxel were diluted with saline just before use for in vivo studies.

Cell lines and culture conditions. Sixteen HNSCC cell lines were examined in this study. The origins of these cell lines were the oral floor (YCU-OR891), hypopharynx (YCUH891), mesopharynx (YCU-M862, KCC-M871, and YCUM911), larynx (KCC-L871, YCU-L891), tongue (KCCT871, KCC-T873, YCU-T891, and YCU-T892), and maxillary sinus (KCC-MS871, YCU-MS861), and metastatic tumors from different tongue carcinomas (KCC-TCM901, KCC-TCM902, and KCC-TCM903). These cell lines were established in the Department of Otolaryngology, Yokohama City University School of Medicine and Research Institute, Kanagawa Cancer Center. All cell lines were maintained in Dulbecco's modification of Eagle's medium (DMEM) (Wako Chemical, Osaka, Japan) supplemented with 10\% fetal bovine serum (Gibco, Grand Island, NY). These cells were incubated at $37^{\circ} \mathrm{C}$ in a moist atmosphere containing $5 \% \mathrm{CO}_{2}$.

In vitro proliferation assays. Cell proliferation assay was performed to assess the effect of treatment on the growth of 16 human HNSCC cell lines. These cells were plated in 96-well flat plates (Sumilon; Sumitomo Bakekite Co., Ltd., Tokyo, Japan) at a concentration of $5 \times 10^{3}$ cells/well. Plates were incubated for $24 \mathrm{~h}$ prior to drug treatment. After $24-\mathrm{h}$ exposure to lapatinib (5 wells of the 96 -well plate per experimental condition), the cell proliferation was assayed by incubating with Tetra Color One (Seikagaku Co., Ltd., Tokyo, Japan). Relative growth inhibition was calculated by dividing the number of recovered drug-treated cells by the number of vehicle-treated control cells.

In vivo antitumor activity studies. Female BALB/c nu/nu nude mice, 6-week old, were obtained from Oriental Yeast (Tokyo, Japan). The mice were maintained in a laminar flow room with a constant temperature and humidity. The animals were maintained and experiments were conducted at the Yokohama City University School of Medicine, Laboratory Animal Facility. The experiments were conducted according to the guidelines for animal experiments set by the Animal Experiment Committee of Yokohama City University School of Medicine. Suspensions of YCU-H891 cells (100 $\mu \mathrm{l})$ (final concentration, $1 \times 10^{7}$ cells $/ 100 \mu \mathrm{l}$ ) were injected s.c. into the right flank of the mice on day 1 . Tumor-bearing mice were randomized $(n=6)$ when the mean tumor volume was $50-100 \mathrm{~mm}^{3}$. Each group was closely matched before treatment, which began one week after cell transplantation. Lapatinib was dissolved in $0.5 \%$ hydroxypropylmethylcellulose and $0.1 \%$ Tween- 80 vehicle and was given once daily by oral gavage. The mice were treated with lapatinib $(50,100,200 \mathrm{mg} / \mathrm{kg})$ from day 8 to day 28 . Cisplatin was administered i.p. (2.5 $\mathrm{mg} / \mathrm{kg} /$ day on day 8$)$. Paclitaxel was administered i.p. ( $7.5 \mathrm{mg} / \mathrm{kg} /$ day 2 times on day 8 and day 15). The control group of mice received hydroxypropylmethylcellulose/Tween- 80 vehicle treatment at the same schedule as lapatinib. Treatment group number was 8. Tumor diameters in the control and treated groups were measured weekly with a Vernier caliper. Tumor volume (V) was determined by the equation: $\mathrm{V}=\mathrm{ab}^{2} / 2$ (a, length; $\mathrm{b}$, width).

Evaluation of apoptosis. Terminal deoxynucleotidyl transferase-mediated cUDP nick end-labeling (TUNEL) was done for the evaluation of apoptosis. This was evaluated using an Apoptosis In Situ Detection Kit (Wako Chemical). The apoptotic index was calculated as the percentage of positive cell nuclei stained with peroxidase in the fields at $\mathrm{x} 400$ magnification relative to the total number of cells from a minimum of five microscopic fields from each section.

Evaluation of vessel density. In order to estimate the vessel density, the vessels in the tumor tissues were stained with an anti-CD31 antibody (1:200; Dako, Denmark). The tumors were excised and blocked with $2 \%$ goat serum and $1 \%$ bovine serum albumin in PBS and stained with the antibody. Slides were developed using 3, 3'-diaminobenzidine substrate biotinylated peroxidase reagent (Vector Laboratories, Inc., Burlingame, CA). Vessel density was determined by counting the stained vessels in the fields at x100 magnification. Five fields per histological section were included in the analysis.

Statistical analysis. For statistical analyses of in vivo antitumor activity, apoptotic index, and vessel density, we used Student's paired t-test.

\section{Results}

Antiproliferative effects of lapatinib on 16 HNSCC cells. We determined the antiproliferative effects of lapatinib at different concentrations $(0-100 \mu \mathrm{M})$ using HNSCC cell lines. As shown in Table I, the $\mathrm{IC}_{50}$ for lapatinib ranged between 13.6 and $60.2 \mu \mathrm{M}$.

In vivo studies of the antitumor effects of lapatinib, alone and in combination with cisplatin or paclitaxel, against HNSCC xenografts. We investigated in vivo antitumor activity of lapatinib alone and in combination with cisplatin or paclitaxel in nude mice bearing YCU-H891 squamous cell carcinoma xenografts. Among 16 HNSCC cell lines, YCU-H891 was somewhat more sensitive to lapatinib. As shown in Fig. 1, lapatinib treatment of nude mice bearing established HNSCC tumor xenografts led to dose-dependent inhibition of tumor growth. Significant inhibition of tumor growth was observed in the $200 \mathrm{mg} / \mathrm{kg}$ treatment group $(\mathrm{P}<0.05)$. But in this group, apparent weight loss of treated mice was found compared with the vehicle control group (data not shown). 
Table I. The antiproliferative activity of lapatinib.

\begin{tabular}{llc}
\hline & & $\mathrm{IC}_{50}(\mu \mathrm{M})$ \\
\cline { 2 - 3 } HNSCC cell lines & Primary site & Lapatinib \\
\hline YCC-OR891 & Oral floor & 13.6 \\
KCC-T871 & Tongue & 22.8 \\
KCC-T873 & Tongue & 33.8 \\
KCC-TCM901 & Lung & 18.7 \\
KCC-TCM902 & Lung & 33.7 \\
KCC-TCM903 & Lung & 21.3 \\
YCU-T891 & Tongue & 22.4 \\
YCU-T892 & Tongue & 30.5 \\
YCU-MS861 & Maxillary sinus & 39.0 \\
KCC-MS871 & Maxillary sinus & 17.8 \\
YCU-M862 & Mesopharynx & 35.2 \\
KCC-M871 & Mesopharynx & 54.2 \\
YCU-M911 & Mesopharynx & 18.8 \\
YCU-H891 & Hypopharynx & 18.2 \\
KCC-L871 & Larynx & 60.2 \\
YCU-L891 & Larynx & 25.1 \\
\hline
\end{tabular}

${ }^{a}$ Metastatic tumors from different tongue carcinomas. In the proliferation assay described in Materials and methods, tumor cells were exposed to lapatinib for $24 \mathrm{~h}$. Data are expressed as $\mathrm{IC}_{50}$, the drug concentration (in $\mu \mathrm{M}$ ) that causes $50 \%$ inhibition of cell proliferation.

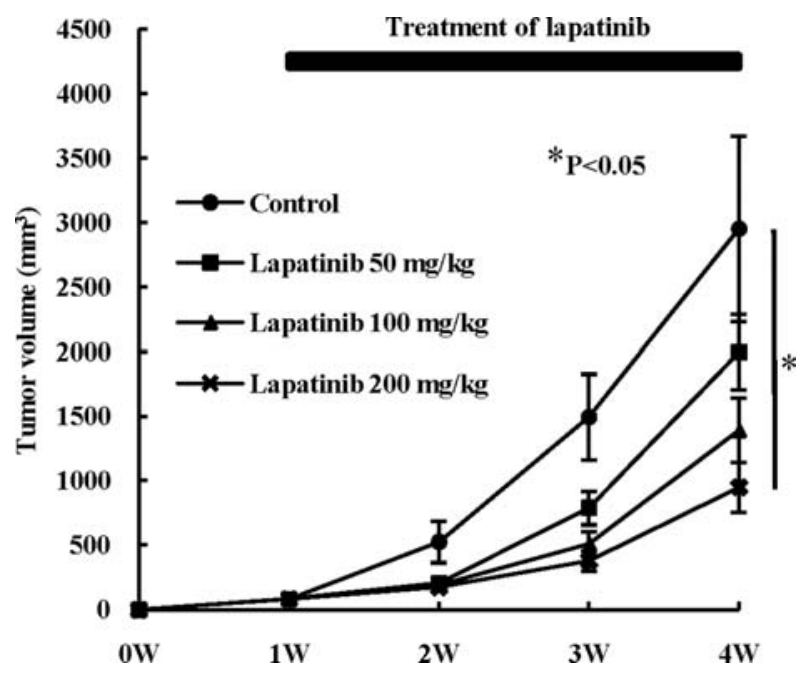

Figure 1. Lapatinib exerts a dose-dependent inhibition on the growth of YCU-H891 tumor xenografts. Data presented are mean values $(n=6$ per group); error bars indicate $\mathrm{SE} .{ }^{*} \mathrm{P}<0.05$ versus control. A significant difference was analyzed by Student's paired t-test.

We also evaluated the combined effects of lapatinib with cisplatin or paclitaxel (Fig. 2). The combination treatment of lapatinib with cisplatin or paclitaxel reduced the tumor

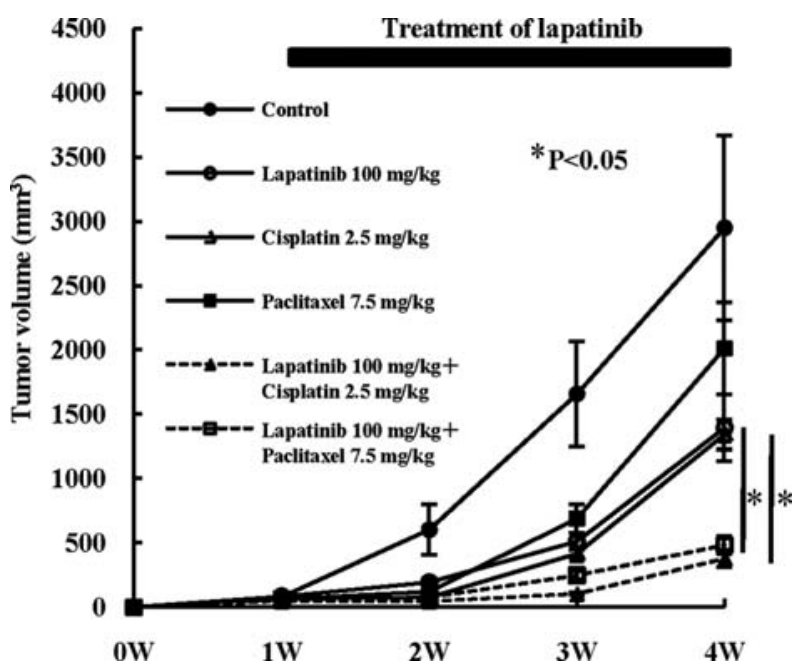

Figure 2. Inhibitory effects of the combination treatment of lapatinib with cisplatin or paclitaxel on the growth of YCU-H891 tumor xenografts. Data presented are mean values ( $\mathrm{n}=6$ per group); error bars indicate $\mathrm{SE} .{ }^{*} \mathrm{P}<0.05$ versus lapatinib alone or cisplatin alone. A significant difference was analyzed by Student's paired t-test.

volume significantly compared to either agent alone at the end of the treatment period $(\mathrm{P}<0.05)$.

Effect of treatment on apoptosis in the xenograft model. Because promotion of apoptosis is a commonly seen antitumor mechanism, we did histopathological analysis of the xenograft samples for apoptosis (Fig. 3). Treatment of lapatinib alone led to a dose-dependent increase in the number of apoptotic (TUNEL-positive) cells. The apoptotic index was significantly higher in tumors treated with 100 or $200 \mathrm{mg} / \mathrm{kg}$ lapatinib compared to the control (vehicle) mice $(\mathrm{P}<0.01)$ (Fig. 4).

The apoptotic index was also significantly higher in tumors from mice treated with lapatinib combined with cisplatin or paclitaxel (compared to either agent alone; $\mathrm{P}<0.01$ ) (Fig. 4).

Effect of treatment on microvascular content in the xenograft model. To determine drug effects on tumor neovascularization, we examined the vessel density of xenograft tumors (Fig. 3). Lapatinib alone inhibited angiogenesis (a lower number of microvessels positive for CD31 staining) compared to the control (vehicle) group. Statistical significance was not observed for the difference between the lapatinib-treated groups and the control group (Fig. 5). The combination treatment of lapatinib with paclitaxel led to a significantly lower number of microvessels positive for CD31 staining (Fig. 5) $(\mathrm{P}<0.01)$; it was not significantly better compared to paclitaxel alone. Combination treatment of lapatinib with cisplatin was not significantly better than the control group.

\section{Discussion}

It is evident that the great majority of HNSCCs express EGFR, and overexpression of EGFR correlates with reduced 
TUNEL $(\times 400)$

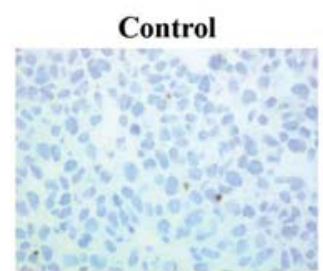

Lapatinib 50 mg/kg

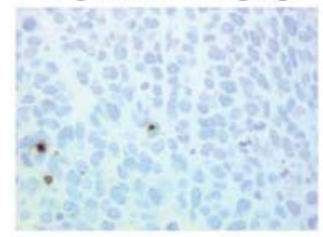

Lapatinib $100 \mathrm{mg} / \mathrm{kg}$

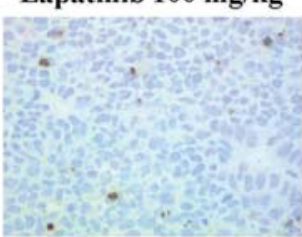

Lapatinib 200 mg/kg

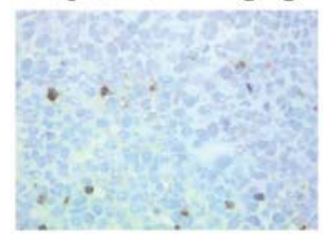

Cisplatin $2.5 \mathrm{mg} / \mathrm{kg}$

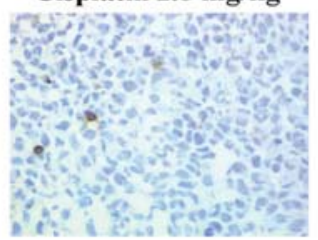

Paclitaxel $7.5 \mathrm{mg} / \mathrm{kg}$

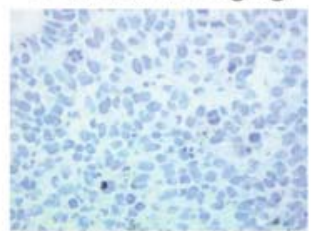

Lapatinib $100 \mathrm{mg} / \mathrm{kg}$

$+$

Cisplatin $2.5 \mathrm{mg} / \mathrm{kg}$



Lapatinib $100 \mathrm{mg} / \mathrm{kg}$ $+$

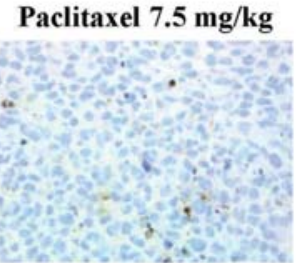

CD31 $(\times 100)$

Control

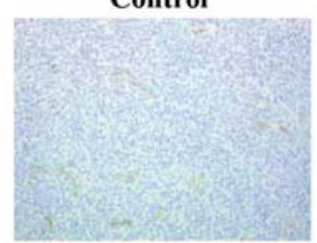

Lapatinib 50 mg/kg

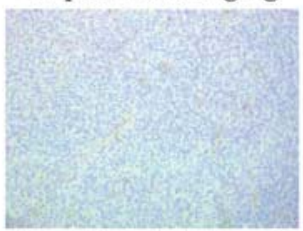

Lapatinib $100 \mathrm{mg} / \mathrm{kg}$



Lapatinib 200 mg/kg

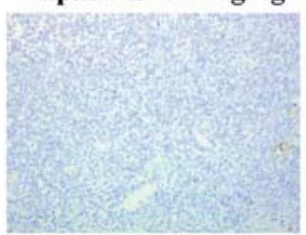

Cisplatin $2.5 \mathrm{mg} / \mathrm{kg}$

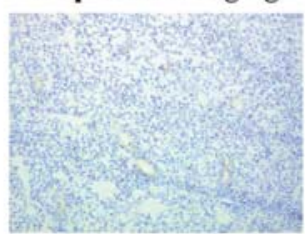

Paclitaxel 7.5 mg/kg

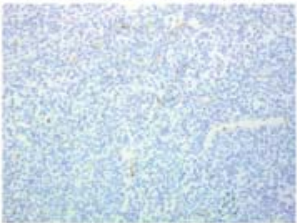

Lapatinib $100 \mathrm{mg} / \mathrm{kg}$

$+$

Cisplatin $2.5 \mathrm{mg} / \mathrm{kg}$

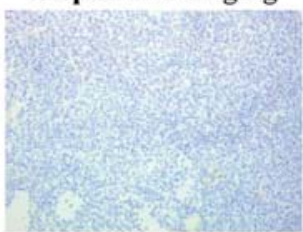

Lapatinib $100 \mathrm{mg} / \mathrm{kg}$ $+$

Paclitaxel $7.5 \mathrm{mg} / \mathrm{kg}$

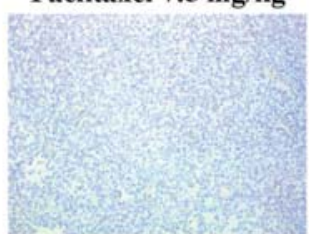

Figure 3. Apoptotic events and vessel density in YCU-H891 tumor xenografts. Terminal deoxynucleotidyl transferase-mediated cUDP nick end-labeling (TUNEL) staining was utilized to evaluate apoptosis (x400). The vessels of tumors were stained with anti-CD31 antibody to evaluate of antiangiogenesis by each treatment $(\mathrm{x} 100)$.

survival, increased risk of recurrence and distant metastasis, and resistance to radiotherapy $(9,18-21)$. On the other hand, overexpression of HER-2 is also associated with poor prognosis in cancers of the breast, ovary, bladder and colon (22-24). HER-2 seems to function primarily as a heterodimerization partner for other HER family members $(25,26)$. EGFR heterodimers produce an intense and sustained proliferative signal that is greater than that for EGFR homodimers $(27,28)$. Therapies that target EGFR and HER-2 were reported to be efficacious against breast cancer, nonsmall cell lung cancer prostate cancer and vulvar squamous cell carcinoma (13-16). We also reported that a therapy that targets HER, gefitinib combined with trastuzumab, has antitumor effect against HNSCC in vitro (17). Accordingly, we examined the antitumor activity of lapatinib, a dual inhibitor of the tyrosine kinase domains of the EGFR and HER-2. We studied HNSCC cells in vitro and in vivo.

In our previous study (17), we studied 16 HNSCC cell lines and were able to calculate an $\mathrm{IC}_{50}$ for gefitinib against proliferation of 11 of the lines after $24 \mathrm{~h}$ of exposure to the drug. In 5 cell lines an $\mathrm{IC}_{50}$ could not be calculated (data not shown). In the present study, we calculated an $\mathrm{IC}_{50}$ for lapatinib for all cell lines after $24 \mathrm{~h}$ of drug exposure. The $\mathrm{IC}_{50}$ for lapatinib ranged between 13.6 and $60.2 \mu \mathrm{M}$ (Table I). These results suggest that HNSCC cells are more sensitive to lapatinib than gefitinib, and that lapatinib is an effective agent for suppressing growth of HNSCC cells in vitro. A correlation was not observed between: i) our in vitro proliferation assays results for lapatinib; and ii) expression of EGFR or HER-2 in the same cell lines that was reported in our study (17) (data not shown).

About sensitivity of EGFR tyrosine kinase inhibitors such as gefitinib, the effect of an activating mutation and an inactivating mutation of the intracellular domain of EGFR have been reported (29-33). Acquired resistance was associated with the emergence of a second mutation in EGFR (a methionine for threonine substitution at amino acid T790M) $(31,34,35)$. Harboring HER-2 mutations and insertion of HER2 mutations correlated with increased resistance to EGFR tyrosine kinase inhibitors (36-39).

Next we investigated the antitumor effects of lapatinib alone or in combination therapy with two chemotherapeutic agents, paclitaxel or cisplatin, in an in vivo study. Lapatinib treatment led to dose-dependent inhibition of tumor growth 


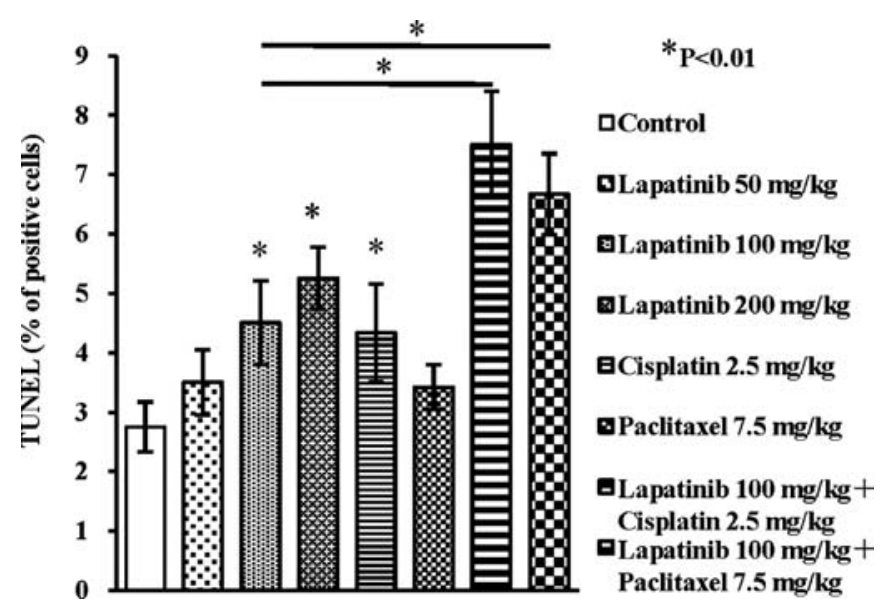

Figure 4. Effects of the treatment with lapatinib alone and combination treatment of lapatinib with cisplatin or paclitaxel on apoptotic index (TUNEL). A statistical significance was observed in the group of lapatinib $100 \mathrm{mg} / \mathrm{kg}$, lapatinib $200 \mathrm{mg} / \mathrm{kg}$ and cisplatin $2.5 \mathrm{mg} / \mathrm{kg}$ compared to the control $(\mathrm{P}<0.01)$. A statistical significance was not observed in the group of the combination treatment of lapatinib with cisplatin or the combination treatment of lapatinib with paclitaxel compared to the lapatinib alone group. Data represent mean values $( \pm \mathrm{SD})$. A significant difference was analyzed by Student's paired t-test.

(Fig. 1). Significant inhibition of tumor growth was observed in the $200 \mathrm{mg} / \mathrm{kg}$ treatment group $(\mathrm{P}<0.05)$, but apparent weight loss of treated mice was observed at this dose. The antitumor effects of lapatinib alone in a breast cancer cell xenograft model in vivo have been reported (40). In that study, $75 \mathrm{mg} / \mathrm{kg}$ of lapatinib daily for 21 days led to significant antitumor activity compared to vehicle control. Regarding colon cancer, Zhou et al reported that lapatinib (200 mg/kg daily) had significant antitumor activity compared to vehicle control. There was $<10 \%$ weight loss compared to the vehicle control (41). These reports indicated that lapatinib at a dose of $200 \mathrm{mg} / \mathrm{kg}$ daily had a significant antitumor effect, but this dose seems to have severe drug toxicity.

Next we investigated the antitumor effect of lapatinib combined with paclitaxel or cisplatin. Each combination decreased tumor growth significantly compared to single agent administration. These chemotherapeutic agents which are available for HNSCC, are good candidates for the combination treatment with lapatinib. A phase I study of lapatinib in combination with chemoradiation in patients with locally advanced HNSCC was reported (12). In that report, cisplatin was used as a chemotherapeutic agent and the overall response rate was $81 \%$. Regarding metastatic breast cancer, a phase II study of lapatinib plus paclitaxel was reported and clinical outcomes improved significantly in HER-2 positive patients (42).

To evaluate apoptosis-mediated antitumor effects of lapatinib in vivo, we used the TUNEL assay. After lapatinib alone, the number of TUNEL-positive tumor cells dosedependently increased and statistical significance was observed compared to the control (vehicle) group. These results indicate that lapatinib induces apoptotic events and has antiproliferative effects on HNSCC cells. It was reported that activation of the EGFR promotes processes responsible

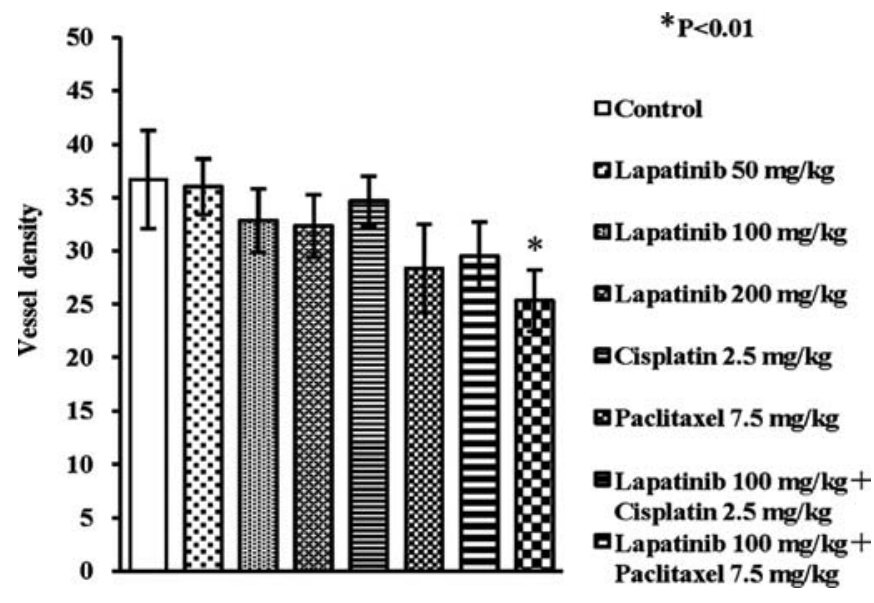

Figure 5. Effects of lapatinib alone and combination treatment of lapatinib with cisplatin or paclitaxel on vessel density (CD31 staining). The treatment of lapatinib alone showed no statistically significat difference at each dose. A significant difference was observed only in the group of the combination treatment of lapatinib with paclitaxel compared to the control $(\mathrm{P}<0.01)$. Data represent mean values $( \pm S D)$. A significant difference was analyzed by Student's paired t-test.

for tumor growth and progression, including proliferation and maturation, angiogenesis, invasion, metastasis, and inhibition of apoptosis (43).

HER-2 seems to function as a heterodimerization partner for other HER family members $(25,26)$. It was reported that EGFR heterodimers produce greater proliferative signal than EGFR homodimers $(27,28)$. Therefore, lapatinib may promote endothelial cell apoptosis via inhibition of the EGFR pathway or heterodimerization of EGFR and HER2. The number of apoptotic events after combination treatment of lapatinib with cisplatin or paclitaxel was higher compared to each single agent administration. Each combination increased the number of apoptotic events. Therefore, both cisplatin and paclitaxel are appropriate partners for lapatinib in combined anticancer therapy.

To evaluate vessel density in vivo, immunohistochemical staining with anti-CD31 antibody was used. The treatment of lapatinib alone decreased the number of CD31-positive endothelial cells, but statistical significance was not observed. The combined treatment of lapatinib with paclitaxel showed significant antiangiogenic activity compared to the control (vehicle) group $(\mathrm{P}<0.01)$. But compared to paclitaxel alone, statistical significance was not observed. It has been reported that paclitaxel shows antiangiogenic activity (44-46), but a synergistic effect with lapatinib was not observed. Cisplatin did not show antiangiogenic activity and the combination treatment of lapatinib with cisplatin had no antiangiogenic activity. Synergistic effects against angiogenesis were not expected in combination treatment with cisplatin.

In conclusion, we show that in vitro lapatinib has antiproliferative effects and that in vivo lapatinib is an active antitumor agent against HNSCC due to its ability to induce tumor cell apoptosis. However, it did not observe an antiangiogenic effect. Lapatinib in combination with cisplatin or paclitaxel causes greater inhibition than either agent alone against HNSCC xenografts in a mouse model; the 
mechanism appears to be enhancement of tumor cell apoptosis.

Based on results of the combination treatment of lapatinib with cisplatin or paclitaxel, the present study provides an experimental basis for the clinical application for HNSCC patients.

\section{References}

1. Eisbruch A, Blick M, Lee JS, Sacks PG and Gutterman J: Analysis of the epidermal growth factor receptor gene in fresh human head and neck tumors. Cancer Res 47: 3603-3605, 1987.

2. Santini J, Formento JL, Francoual M, et al: Characterization, quantification, and potential clinical value of the epidermal growth factor receptor in head and neck squamous cell carcinomas. Head Neck 13: 132-139, 1991.

3. Dassonville O, Formento JL, Francoual M, et al: Expression of epidermal growth factor receptor and survival in upper aerodigestive tract cancer. J Clin Oncol 11: 1873-1878, 1993.

4. Olayioye MA, Neve RM, Lane HA and Hynes NE: The ErbB signaling network: receptor heterodimerization in development and cancer. EMBO J 19: 3159-3167, 2000.

5. Khademi B, Shirazi FM, Vasei M, et al: The expression of $\mathrm{p} 53$, c-erbB-1 and c-erbB-2 molecules and their correlation with prognostic markers in patients with head and neck tumors. Cancer Lett 184: 223-230, 2002.

6. Pornchai OC, Rhys-Evans PH, Modjtahedi $\mathrm{H}$ and Eccles SA The role of c-erbB receptors and ligands in head and neck squamous cell carcinoma. Oral Oncol 38: 627-640, 2002.

7. Alaoui-Jamali MA, Paterson J, Al Moustafa AE and Yen L: The role of ErbB-2 tyrosine kinase receptor in cellular intrinsic chemoresistance: mechanisms and implications. Biochem Cell Biol 75: 315-325, 1997.

8. Rogers SJ, Harrington KJ, Rhys-Evans P, Pornchai OC and Eccles SA: Biological significance of c-erbB family oncogenes in head and neck cancer. Cancer Metastasis Rev 24: 47-69, 2005

9. Ang KK, Berkey BA, Tu X, et al: Impact of epidermal growth factor receptor expression on survival and pattern of relapse in patients with advanced head and neck carcinoma. Cancer Res 62: 7350-7356, 2002.

10. Shewchuk L, Hassell A, Wisely B, et al: Binding mode of the 4-anilinoquinazoline class of protein kinase inhibitor: X-ray crystallographic studies of 4-anilinoquinazolines bound to cyclin-dependent kinase 2 and p38 kinase. J Med Chem 43: $133-138,2000$

11. Agulnik M, Cohen EW, Cohen RB, et al: Phase II study of lapatinib in recurrent or metastatic epidermal growth factor receptor and/or erbB2 expressing adenoid cystic carcinoma and non adenoid cystic carcinoma malignant tumors of the salivary glands. J Clin Oncol 25: 3978-3984, 2007.

12. Harrington KJ, El-Hariry IA, Holford CS, et al: Phase I study of lapatinib in combination with chemoradiation in patients with locally advanced squamous cell carcinoma of the head and neck. J Clin Oncol 27: 1100-1107, 2009.

13. Formento P, Hannoun-Levi JM, Fischel JL, Magne N, Etienne-Grimaldi MC and Milano G: Dual HER 1-2 targeting of hormone-refractory prostate cancer by ZD1839 and trastuzumab. Eur J Cancer 40: 2837-2844, 2004.

14. Warburton C, Dragowska WH, Gelmon K, et al: Treatment of HER-2/neu overexpressing breast cancer xenograft models with trastuzumab (Herceptin) and gefitinib (ZD1839): drug combination effects on tumor growth, HER-2/neu and epidermal growth factor receptor expression, and viable hypoxic cell fraction. Clin Cancer Res 10: 2512-2524, 2004.

15. Nakamura H, Takamori S, Fujii T, et al: Cooperative cell-growth inhibition by combination treatment with ZD1839 (Iressa) and trastuzumab (Herceptin) in non-small-cell lung cancer. Cancer Lett 230: 33-46, 2005.

16. Fukutome M, Maebayashi K, Nasu S, Seki K and Mitsuhashi N: Enhancement of radiosensitivity by dual inhibition of the HER family with ZD1839 ('Iressa') and trastuzumab ('Herceptin'). Int J Radiat Oncol Biol Phys 66: 528-536, 2006

17. Kondo N, Ishiguro Y, Kimura M, et al: Antitumor effect of gefitinib on head and neck squamous cell carcinoma enhanced by trastuzumab. Oncol Rep 20: 373-378, 2008.
18. Grandis JR and Tweardy DJ: Elevated levels of transforming growth factor alpha and epidermal growth factor receptor messenger RNA are early markers of carcinogenesis in head and neck cancer. Cancer Res 53: 3579-3584, 1993.

19. Rubin Grandis J, Melhem MF, Gooding WE, et al: Levels of TGF-alpha and EGFR protein in head and neck squamous cell carcinoma and patient survival. J Natl Cancer Inst 90: 824-832, 1998.

20. Huang SM, Li J, Armstrong EA and Harari PM: Modulation of radiation response and tumor-induced angiogenesis after epidermal growth factor receptor inhibition by ZD1839 (Iressa). Cancer Res 62: 4300-4306, 2002.

21. Bei R, Budillon A, Masuelli L, et al: Frequent overexpression of multiple ErbB receptors by head and neck squamous cell carcinoma contrasts with rare antibody immunity in patients. J Pathol 204: 317-325, 2004.

22. Slamon DJ, Godolphin W, Jones LA, et al: Studies of the HER-2/ neu proto-oncogene in human breast and ovarian cancer. Science 244: 707-712, 1989.

23. Zhau HE, Zhang X, von Eschenbach AC, et al: Amplification and expression of the c-erb B-2/neu proto-oncogene in human bladder cancer. Mol Carcinog 3: 254-257, 1990.

24. Kapitanovic S, Radosevic S, Kapitanovic M, et al: The expression of $\mathrm{p} 185$ (HER-2/neu) correlates with the stage of disease and survival in colorectal cancer. Gastroenterology 112: 1103-1113, 1997

25. Erjala K, Sundvall M, Junttila TT, et al: Signaling via ErbB2 and ErbB3 associates with resistance and epidermal growth factor receptor (EGFR) amplification with sensitivity to EGFR inhibitor gefitinib in head and neck squamous cell carcinoma cells. Clin Cancer Res 12: 4103-4111, 2006.

26. Graus-Porta D, Beerli RR, Daly JM and Hynes NE: ErbB-2, the preferred heterodimerization partner of all ErbB receptors, is a mediator of lateral signaling. EMBO J 16: 1647-1655, 1997.

27. Pinkas-Kramarski R, Soussan L, Waterman H, et al: Diversification of Neu differentiation factor and epidermal growth factor signaling by combinatorial receptor interactions. EMBO J 15: 2452-2467, 1996.

28. Karunagaran D, Tzahar E, Beerli RR, et al: ErbB-2 is a common auxiliary subunit of NDF and EGF receptors: implications for breast cancer. EMBO J 15: 254-264, 1996.

29. Taguchi T, Tsukuda M, Imagawa-Ishiguro Y, Kato Y and Sano D: Involvement of EGFR in the response of squamous cell carcinoma of the head and neck cell lines to gefitinib. Oncol Rep 19: 65-71, 2008.

30. Loeffler-Ragg J, Witsch-Baumgartner M, Tzankov A, et al: Low incidence of mutations in EGFR kinase domain in Caucasian patients with head and neck squamous cell carcinoma. Eur J Cancer 42: 109-111, 2006.

31. Pao W, Miller VA, Politi KA, et al: Acquired resistance of lung adenocarcinomas to gefitinib or erlotinib is associated with a second mutation in the EGFR kinase domain. PLoS Med 2: e73, 2005.

32. Paez JG, Janne PA, Lee JC, et al: EGFR mutations in lung cancer: correlation with clinical response to gefitinib therapy. Science 304: 1497-1500, 2004

33. Cappuzzo F, Magrini E, Ceresoli GL, et al: Akt phosphorylation and gefitinib efficacy in patients with advanced non-small-cell lung cancer. J Natl Cancer Inst 96: 1133-1141, 2004.

34. Balak MN, Gong Y, Riely GJ, et al: Novel D761Y and common secondary T790M mutations in epidermal growth factor receptormutant lung adenocarcinomas with acquired resistance to kinase inhibitors. Clin Cancer Res 12: 6494-6501, 2006.

35. Kosaka T, Yatabe Y, Endoh H, et al: Analysis of epidermal growth factor receptor gene mutation in patients with nonsmall cell lung cancer and acquired resistance to gefitinib. Clin Cancer Res 12: 5764-5769, 2006.

36. Cappuzzo F, Ligorio C, Janne PA, et al: Prospective study of gefitinib in epidermal growth factor receptor fluorescence in situ hybridization-positive/phospho-Akt-positive or never smoker patients with advanced non-small-cell lung cancer: the ONCOBELL trial. J Clin Oncol 25: 2248-2255, 2007.

37. Sasaki H, Endo K, Takada M, et al: EGFR exon 20 insertion mutation in Japanese lung cancer. Lung Cancer 58: 324-328, 2007.

38. Stephens P, Hunter C, Bignell G, et al: Lung cancer: intragenic ERBB2 kinase mutations in tumours. Nature 431: 525-526, 2004. 
39. Shimamura T, Ji H, Minami Y, et al: Non-small-cell lung cancer and $\mathrm{Ba} / \mathrm{F} 3$ transformed cells harboring the ERBB2 G776insV_G/C mutation are sensitive to the dual-specific epidermal growth factor receptor and ERBB2 inhibitor HKI272. Cancer Res 66: 6487-6491, 2006.

40. Konecny GE, Pegram MD, Venkatesan N, et al: Activity of the dual kinase inhibitor lapatinib (GW572016) against HER-2overexpressing and trastuzumab-treated breast cancer cells Cancer Res 66: 1630-1639, 2006.

41. Zhou Y, Li S, Hu YP, et al: Blockade of EGFR and ErbB2 by the novel dual EGFR and ErbB2 tyrosine kinase inhibitor GW572016 sensitizes human colon carcinoma GEO cells to apoptosis. Cancer Res 66: 404-411, 2006.

42. Di Leo A, Gomez HL, Aziz Z, et al: Phase III, double-blind, randomized study comparing lapatinib plus paclitaxel with placebo plus paclitaxel as first-line treatment for metastatic breast cancer. J Clin Oncol 26: 5544-5552, 2008.
43. Rocha-Lima CM, Soares HP, Raez LE and Singal R: EGFR targeting of solid tumors. Cancer Control 14: 295-304, 2007.

44. Fox WD, Higgins B, Maiese KM, et al: Antibody to vascular endothelial growth factor slows growth of an androgenindependent xenograft model of prostate cancer. Clin Cancer Res 8: 3226-3231, 2002.

45. Sweeney CJ, Miller KD, Sissons SE, et al: The antiangiogenic property of docetaxel is synergistic with a recombinant humanized monoclonal antibody against vascular endothelial growth factor or 2-methoxyestradiol but antagonized by endothelial growth factors. Cancer Res 61: 3369-3372, 2001.

46. Belotti D, Vergani V, Drudis T, et al: The microtubule-affecting drug paclitaxel has antiangiogenic activity. Clin Cancer Res 2: $1843-1849,1996$. 